\title{
Sistema de geoespacialização da demanda de irrigação suplementar para o Estado de Minas Gerais I: Descrição'
}

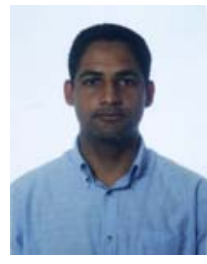

Marcos O. Santana ${ }^{2}$, Aristides Ribeiro ${ }^{3} \&$ Gilberto C. Sediyama ${ }^{4}$

\footnotetext{
1 Parte da Dissertação de Mestrado apresentada pelo primeiro autor na UFV. Viçosa, MG

2 DEA/UFV. Viçosa, MG. Fone: (31) 3899-1905, Fax: (31) 3899-2735. E-mail: santana@alunos.ufv.br (Foto)

3 DEA/UFV. Viçosa, MG. Fone: (31) 3899-1906. E-mail: ribeiro@ufv.br

4 DEA/UFV. Viçosa, MG. Fone: (31) 3899-1905. E-mail: sediyama@ufv.br
}

Protocolo 124 - 29/8/2002 - Aprovado em 21/2/2003

\begin{abstract}
Resumo: Com este trabalho objetivou-se desenvolver um sistema automático e monitorado de regionalização da demanda de irrigação suplementar das principais culturas irrigadas no Estado de Minas Gerais, disponibilizando tais informações via rede mundial de computadores (Internet) com três atualizações semanais. O sistema, denominado IRGNET, utiliza dados de estações climáticas automáticas do Instituto Nacional de Pesquisas Espaciais (INPE) para estimativa da perda de água pela cultura por evapotranspiração e a reposição da água no solo, pela precipitação. Utilizou-se um sistema de informações geográficas para espacializar e gerar mapas temáticos de evapotranspiração de referência e de precipitação diária do Estado e se desenvolveu um programa computacional para calcular o balanço hídrico e determinar a lâmina de irrigação para qualquer localidade do Estado.
\end{abstract}

Palavras-chave: balanço hídrico, sistema de informações geográficas, internet

\section{Geospatialization system for demand of supplemental irrigation in the State of Minas Gerais I: Description}

\begin{abstract}
This study had the aim to develop an automatic and controlled system of regionalized supplemental irrigation demand for the main irrigated crops in the State of Minas Gerais by providing this information three times a week by the World Wide Web (Internet). The so-called IRGNET system uses data collected by automatic weather stations belonging to the National Institute for Space Research (INPE) for the assessment of water loss in crop evapotranspiration and also the water supply by rainfall. A geographic information system was used to spatialize and create thematic maps about crop evapotranspiration and daily rainfall in the State. A computer program was also developed to calculate the soil water balance and to determine the irrigation water depth for any place within the State.
\end{abstract}

Key words: water balance, geographic information system, internet

\section{INTRODUÇÃO}

O êxito da prática da irrigação se baseia no planejamento cuidadoso, envolvendo desde a fase de projeto até a operação e o manejo do sistema de irrigação. O conhecimento da quantidade de água necessária para o bom desenvolvimento da cultura é vital para o manejo de áreas irrigadas. Assim, também o acompanhamento da entrada e saída de água no solo em curtos períodos permite, ao técnico irrigacionista, ação mais efetiva, impedindo que as plantas sofram déficit hídrico evitando, desta forma, o comprometimento da máxima produção. O mau dimensionamento dos sistemas de irrigação e o emprego de lâminas de água de reposição inadequadas, comprometem não apenas o potencial de produção da cultura mas, também, os recursos hídricos disponíveis. A aplicação de lâminas de água excessivas aumenta os custos de produção, além de promover a lixiviação de nutrientes do solo e comprometer o abastecimento das usinas hidroelétricas, propriedades e aglomerados urbanos situados à jusante. A aplicação de lâminas menores que o necessário à cultura implica em queda na produção e, muitas vezes, salinização do solo.

As séries históricas de dados climáticos são muito úteis para o dimensionamento de sistemas de irrigação e, muitas vezes, têm sido empregadas para estimativa estatística da demanda de irrigação; entretanto, a grande variabilidade interanual do clima compromete a exatidão dessas estimativas para uso em manejo, indicando ser mais adequada a utilização de dados climáticos em tempo real. 
O número de estações meteorológicas principais no Brasil ainda é insuficiente para uma boa cobertura do território nacional, o que tem dificultado a boa caracterização das condições atmosféricas. Em Israel, país com extensão territorial semelhante à do Estado de Sergipe e com destaque na utilização da irrigação, existem 70 estações meteorológicas, enquanto Minas Gerais, com uma área aproximadamente 28 vezes maior contava, até bem pouco tempo, com apenas 32 estações mantidas pelo Instituto Nacional de Meteorologia. Aliado a isso, não existia sistema público eficiente de disponibilização dos dados coletados, inviabilizando a geração de produtos de clima em tempo hábil para a tomada eficiente de decisões agrícolas.

Nesse contexto vêm surgindo, no Brasil, núcleos de previsão climática estaduais que melhor adequam os produtos gerados às necessidades de cada Estado. Esses núcleos vêm adquirindo plataformas de coleta de dados com transmissão de dados em tempo real via satélite, disponibilizando-os via Internet.

Utilizando-se dados climáticos de Minas Gerais e Estados circunvizinhos, obtidos via Internet, o propósito deste trabalho foi criar um sistema automático de monitoramento de regionalização da demanda de irrigação suplementar das principais culturas irrigadas no Estado de Minas Gerais, disponibilizando tais informações via rede mundial de computadores.

\section{MATERIAL E MÉTODOS}

\section{Região de estudo}

A região de estudo abrangeu todo o Estado de Minas Gerais, situado na Região Sudeste do País, entre os paralelos $14^{\circ} 13^{\prime}$ e $22^{\circ} 55^{\prime}$ de latitude Sul e os meridianos $39^{\circ} 51^{\prime}$ e $51^{\circ} 02^{\prime}$ de longitude Oeste. O Estado se caracteriza por apresentar topografia irregular e, segundo a classificação de Köppen, os seguintes tipos climáticos: Aw, BSw, Cwa e Cwb, significando que podem ser encontradas desde regiões com clima semiárido até regiões com clima tropical chuvoso com inverno seco. As formas predominantes de cobertura vegetal são as seguintes: floresta úmida costeira, floresta seca, floresta subtropical mista, cerrado e campo (Minas Gerais, 1990).

\section{Base de dados}

Os dados meteorológicos foram obtidos no Centro de Missão de Coleta de Dados (CMCD) do Instituto Nacional de Pesquisas Espaciais (INPE). Na Tabela 1 apresentam-se as coordenadas geográficas das Plataformas de Coleta de Dados (PCDs) utilizadas no desenvolvimento do sistema IRGNET.

As PCDs são dotadas de sensores capazes de medir a umidade relativa, temperatura do ar, radiação solar, pressão atmosférica, precipitação, velocidade e direção do vento. Os dados são coletados em intervalos de 10 min, e são calculadas as médias ou as integrações a cada três horas, sendo essas informações armazenadas em um sistema de aquisição de dados. Tais registros são enviados, a cada três horas, ao CMCD via satélite, por ocasião da passagem do satélite de coleta de dados de segunda geração, SCD-2, que tem, como missão, a coleta de dados ambientais. No CMCD os dados são validados e disponibilizados na Internet (INPE, 2002). Além das PCDs localizadas no Estado de Minas Gerais, foram utilizadas estações
Tabela 1. Localização geográfica das plataformas de coleta de dados do CMCD/INPE utilizadas no sistema IRGNET

\begin{tabular}{|c|c|c|c|c|}
\hline Cidade & UF & Latitude $\mathrm{S}$ & Longitude W & Altitude \\
\hline Anagé & $\mathrm{BA}$ & $14^{\circ} 36^{\prime}$ & $41^{\circ} 08^{\prime}$ & 384 \\
\hline Anápolis & GO & $16^{\circ} 19^{\prime}$ & $48^{\circ} 57^{\prime}$ & 1017 \\
\hline Araçuaí & MG & $16^{\circ} 52^{\prime}$ & $42^{\circ} 03^{\prime}$ & 307 \\
\hline Barretos & SP & $20^{\circ} 33^{\prime}$ & $48^{\circ} 34^{\prime}$ & 530 \\
\hline Barro Alto & GO & $14^{\circ} 58^{\prime}$ & $48^{\circ} 54^{\prime}$ & 705 \\
\hline Belo Horizonte & MG & $19^{\circ} 55^{\prime}$ & $43^{\circ} 56^{\prime}$ & 858 \\
\hline Brumado & $\mathrm{BA}$ & $14^{\circ} 09^{\prime}$ & $41^{\circ} 39^{\prime}$ & 422 \\
\hline Cachoeira Paulista & SP & $22^{\circ} 40^{\prime}$ & $45^{\circ} 31^{\prime}$ & 521 \\
\hline Caldas Novas & $\mathrm{GO}$ & $17^{\circ} 45^{\prime}$ & $48^{\circ} 37^{\prime}$ & 686 \\
\hline Caratinga & MG & $22^{\circ} 39^{\prime}$ & $45^{\circ} 31^{\prime}$ & 578 \\
\hline Catalão & GO & $18^{\circ} 10^{\prime}$ & $47^{\circ} 57^{\prime}$ & 835 \\
\hline Ceres & GO & $15^{\circ} 18^{\prime}$ & $49^{\circ} 35^{\prime}$ & 571 \\
\hline Crixás & GO & $14^{\circ} 32^{\prime}$ & $49^{\circ} 58^{\prime}$ & 389 \\
\hline Cruzeiro & SP & $22^{\circ} 34^{\prime}$ & $44^{\circ} 57^{\prime}$ & 517 \\
\hline Cunha & SP & $23^{\circ} 07^{\prime}$ & $45^{\circ} 07^{\prime}$ & 950 \\
\hline Eunápolis & BA & $16^{\circ} 19^{\prime}$ & $39^{\circ} 35^{\prime}$ & 189 \\
\hline Goiânia & GO & $16^{\circ} 44^{\prime}$ & $49^{\circ} 15^{\prime}$ & 749 \\
\hline Goiatuba & GO & $18^{\circ} 01^{\prime}$ & $49^{\circ} 22^{\prime}$ & 774 \\
\hline Ipatinga & MG & $19^{\circ} 28^{\prime}$ & $42^{\circ} 31^{\prime}$ & 240 \\
\hline Itajubá & MG & $22^{\circ} 26^{\prime}$ & $45^{\circ} 27^{\prime}$ & 856 \\
\hline Itumbiara & GO & $18^{\circ} 25^{\prime}$ & $49^{\circ} 12^{\prime}$ & 448 \\
\hline Jaíba & MG & $15^{\circ} 20^{\prime}$ & $43^{\circ} 40^{\prime}$ & 474 \\
\hline Jataí & GO & $17^{\circ} 53^{\prime}$ & $51^{\circ} 43^{\prime}$ & 696 \\
\hline Jequié & BA & $13^{\circ} 51^{\prime}$ & $40^{\circ} 04^{\prime}$ & 215 \\
\hline Lavras & MG & $21^{\circ} 14^{\prime}$ & $45^{\circ} 00^{\prime}$ & 919 \\
\hline Leopoldina & MG & $21^{\circ} 30^{\prime}$ & $42^{\circ} 45^{\prime}$ & 212 \\
\hline Montes Claros & MG & $16^{\circ} 42^{\prime}$ & $43^{\circ} 52^{\prime}$ & 648 \\
\hline Nanuque & MG & $17^{\circ} 50^{\prime}$ & $40^{\circ} 21^{\prime}$ & 103 \\
\hline Paracatu & MG & $17^{\circ} 12^{\prime}$ & $46^{\circ} 52^{\prime}$ & 687 \\
\hline Pirapora & MG & $17^{\circ} 19^{\prime}$ & $44^{\circ} 54^{\prime}$ & 489 \\
\hline Pires do Rio & GO & $17^{\circ} 18^{\prime}$ & $48^{\circ} 15^{\prime}$ & 758 \\
\hline Queluz & $\mathrm{SP}$ & $22^{\circ} 32^{\prime}$ & $44^{\circ} 45^{\prime}$ & 497 \\
\hline Quirinópolis & GO & $18^{\circ} 26^{\prime}$ & $50^{\circ} 27^{\prime}$ & 541 \\
\hline Rio Verde & GO & $17^{\circ} 47^{\prime}$ & $50^{\circ} 55^{\prime}$ & 715 \\
\hline S. J. Barreiro & SP & $22^{\circ} 37^{\prime}$ & $44^{\circ} 35^{\prime}$ & 510 \\
\hline Santa Helena & GO & $17^{\circ} 48^{\prime}$ & $50^{\circ} 35^{\prime}$ & 562 \\
\hline Silveira & $\mathrm{SP}$ & $22^{\circ} 39^{\prime}$ & $44^{\circ} 52^{\prime}$ & 615 \\
\hline Teixeira de Freitas & $\mathrm{BA}$ & $17^{\circ} 32^{\prime}$ & $39^{\circ} 43^{\prime}$ & 186 \\
\hline Vianópolis & $\mathrm{GO}$ & $16^{\circ} 44^{\prime}$ & $48^{\circ} 30^{\prime}$ & 1002 \\
\hline Viçosa & MG & $20^{\circ} 45^{\prime}$ & $42^{\circ} 51^{\prime}$ & 648 \\
\hline Vitória da Conquista & $\mathrm{BA}$ & $14^{\circ} 51^{\prime}$ & $40^{\circ} 50^{\prime}$ & 923 \\
\hline
\end{tabular}

situadas em outros Estados, próximos à divisa de Minas Gerais, a fim de melhorar a interpolação (Tabela 1).

Posteriormente, serão incorporados ao sistema dados de estações climatológicas telemétricas e estações pluviométricas da Companhia Energética do Estado de Minas Gerais (CEMIG).

\section{Desenvolvimento do sistema IRGNET}

Foram desenvolvidos um sistema denominado IRGNET, para disponibilizar na Internet mapas de evapotranspiração de referência (ETo) e de precipitação, e um programa computacional, para calcular o balanço de água no solo e determinar a demanda de irrigação suplementar para qualquer coordenada geográfica do Estado de Minas Gerais. Tais informações são disponibilizadas via Internet, com três atualizações semanais, juntamente com o programa para o cálculo do balanço hídrico. Na Figura 1 apresenta-se o fluxograma do sistema.

O descarregamento dos dados do CMCD/INPE na Internet é feito automaticamente, através de uma rotina desenvolvida 


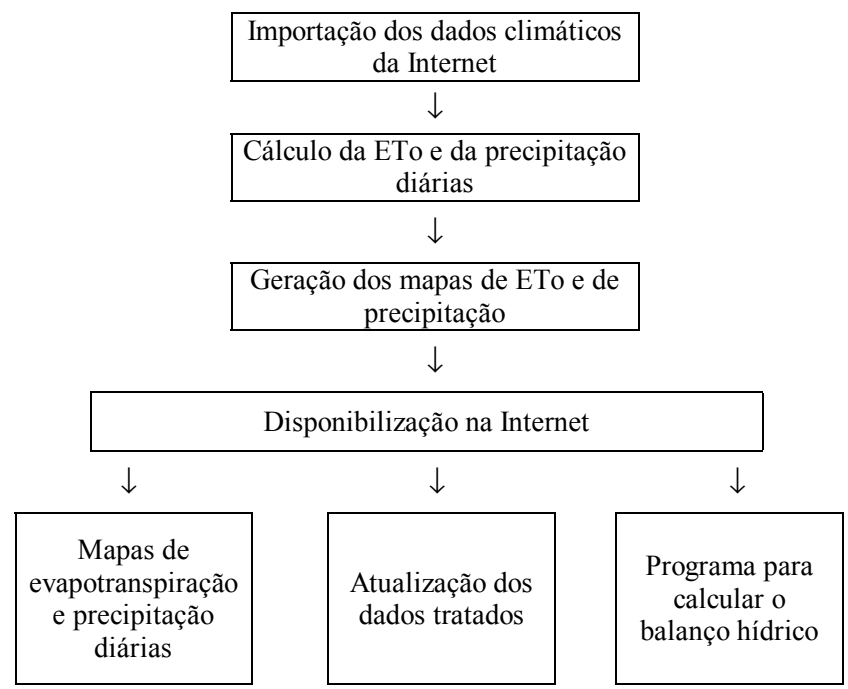

Figura 1. Fluxograma do sistema IRGNET

para tal. Também, foi desenvolvida uma rotina de cálculos em linguagem Visual Basic 6.0, para verificar falhas nos dados climáticos, calcular as médias e integrações diárias destes e calcular a ETo diária gerando, como saída, arquivos georreferenciados de ETo e de precipitação, para ser feita a espacialização.

\section{Cálculo da evapotranspiração de referência}

Para estimativa da evapotranspiração de referência (ETo) utilizou-se o método Penman-Monteith padrão FAO que admite resistência da superfície vegetada de $70 \mathrm{~s} \mathrm{~m}^{-1}$ e calcula a resistência aerodinâmica para uma cultura hipotética de $0,12 \mathrm{~m}$ de altura uniforme e com albedo de $23 \%$. Assim, a evapotranspiração de referência diária pode ser expressa pela Eq. 1 (Allen et al., 1998).

$$
\text { ETo }=\frac{0,409 \Delta\left(\mathrm{R}_{\mathrm{n}}-\mathrm{G}\right)+\gamma\left(\frac{900}{\mathrm{~T}+273}\right) \mathrm{U}_{2}\left(\mathrm{e}_{\mathrm{s}}-\mathrm{e}_{\mathrm{a}}\right)}{\Delta+\gamma\left(1+0,34 \mathrm{U}_{2}\right)}
$$

em que:

ETo - evapotranspiração de referência, $\mathrm{mm} \mathrm{d}^{-1}$

$\mathrm{R}_{\mathrm{n}} \quad$ - saldo de radiação, $M J \mathrm{~m}^{-2} \mathrm{~d}^{-1}$

$\mathrm{G}$ - fluxo de calor no solo, $\mathrm{MJ} \mathrm{m}^{-2} \mathrm{~d}^{-1}$

$\mathrm{T}$ - temperatura média diária a $2 \mathrm{~m}$ de altura, ${ }^{\circ} \mathrm{C}$

$\mathrm{U}_{2}$ - velocidade do vento a $2 \mathrm{~m}$ de altura, $\mathrm{m} \mathrm{s}^{-1}$

$\mathrm{e}_{\mathrm{a}} \quad$ - pressão de vapor de saturação, $\mathrm{kPa}$

$\mathrm{e}_{\mathrm{d}} \quad$ - pressão parcial de vapor, $\mathrm{kPa}$

$\mathrm{e}_{\mathrm{s}}-\mathrm{e}_{\mathrm{a}}$ - déficit de pressão de saturação, $\mathrm{kPa}$

$\Delta \quad$ - declividade da curva de pressão de vapor, $\mathrm{kPa}^{\circ} \mathrm{C}^{-1}$

$\gamma \quad$ - fator psicrométrica, $\mathrm{kPa}^{\circ} \mathrm{C}^{-1}$

O procedimento de cálculo dos parâmetros da equação de Penman-Monteith está descrito detalhadamente em Allen et al. (1998).

\section{Espacialização dos resultados}

Utilizou-se o sistema de informações geográficas IDRISI 3.2 para regionalizar a precipitação e a ETo no Estado de
Minas Gerais (Eastman, 1995). O mapa vetorial de contorno do Estado foi obtido por meio da importação de arquivos disponíveis na página da Internet do Projeto Geominas (www.geominas.mg.gov.br).

Os arquivos em formato ASCII foram convertidos em arquivos vetoriais através do módulo de importação Xyzidris, do IDRISI. O resultado da conversão foi interpolado através do módulo Interpol do IDRISI 3.2. Este comando utiliza um interpolador linear em que o peso a ser interpolado é dado por uma média ponderada que emprega o valor dos pontos de controle mais próximos ponderados pelo inverso da distância, elevado a determinado expoente. O interpolador do IDRISI utiliza um raio de busca variável que pode usar os seis pontos amostrados mais próximos, ou todos os pontos de controle. Neste estudo optou-se por utilizar a primeira opção e o expoente da função da distância igual a 4 que, em estudos preliminares, apresentou melhores resultados para o caso em questão. Os mapas resultantes da interpolação foram filtrados através do módulo Filter e reclassificados, usando-se o módulo Reclass. Logo após, foram sobrepostos ao mapa de contorno de Minas Gerais, com o módulo Overlay e, finalmente, transformados em figuras, através do módulo BMPIDRIS. Todos esses passos realizados no IDRISI foram automatizados por meio de macros que permitem agrupar os diferentes módulos do programa. Os resultados finais foram mapas de ETo e de precipitação diárias no Estado de Minas Gerais, disponibilizados na Internet. Descrições mais detalhadas a respeito dos módulos do IDRISI, citados anteriormente, podem ser encontradas em Eastman (1995).

\section{Cálculo do balanço de água no solo}

O balanço de água no solo pode ser representado em termos do déficit de água no solo, tendo como referencial a umidade na capacidade de campo, sendo descrito pela Eq. 2 .

$$
\mathrm{DA}_{\mathrm{i}}=\mathrm{DA}_{\mathrm{i}-1}+\left(\mathrm{ETr}_{\mathrm{i}}+\mathrm{Pp}_{\mathrm{i}}\right)-\mathrm{P}_{\mathrm{i}}
$$

em que

$\mathrm{DA}_{\mathrm{i}}$ - déficit de água no período $\mathrm{i}, \mathrm{mm} \mathrm{d}^{-1}$

$\mathrm{DA}_{\mathrm{i}-1}$ - déficit de água no período anterior a $\mathrm{i}, \mathrm{mm} \mathrm{d}^{-1}$

$\mathrm{ETr}_{\mathrm{i}}$ - evapotranspiração real da cultura no período i, $\mathrm{mm} \mathrm{d}^{-1}$

$\mathrm{Pp}_{\mathrm{i}}$ - perda por percolação no período $\mathrm{i}, \mathrm{mm} \mathrm{d}^{-1}$

$\mathrm{P}_{\mathrm{i}} \quad$ - precipitação no período $\mathrm{i}, \mathrm{mm} \mathrm{d}^{-1}$

A evapotranspiração real da cultura foi calculada a partir da Eq. 3 (Bernardo, 1995):

$$
\mathrm{ETr}=\mathrm{ks} \mathrm{kc} \mathrm{ETo}
$$

em que:

ETr - evapotranspiração real da cultura, $\mathrm{mm} \mathrm{d}^{-1}$

ks - coeficiente de umidade do solo, adimensional

kc - coeficiente de cultura, adimensional

ETo - evapotranspiração de referência, $\mathrm{mm} \mathrm{d}^{-1}$

O coeficiente de cultura e a duração dos estádios de crescimento das culturas foram adaptados de Doorenbos \& Kassam (1994) e Doorenbos \& Pruitt (1997). 

Eq. 4:

O coeficiente de umidade do solo pode ser estimado pela

$$
\mathrm{ks}=\frac{\ln (\mathrm{LAA}+1)}{\ln (\mathrm{CTA}+1)}
$$

em que LAA é a lâmina real de água no solo, dada em mm, e CTA a capacidade total de água no solo, em mm, expressa pelas seguintes equações:

$$
\begin{aligned}
\mathrm{LAA} & =\frac{(\mathrm{Ua}-\mathrm{Pm})}{10} \mathrm{Da} \operatorname{Pr} \\
\mathrm{CTA} & =\frac{(\mathrm{Cc}-\mathrm{Pm})}{10} \mathrm{Da} \operatorname{Pr}
\end{aligned}
$$

em que:

Ua - umidade atual do solo, $\%$ em peso

$\mathrm{Cc}$ - capacidade de campo, $\%$ em peso

$\mathrm{Pm}$ - ponto de murchamento, $\%$ em peso

$\mathrm{Da}$ - densidade do solo, $\mathrm{kg} \mathrm{dm}^{-3}$

Pr - profundidade do sistema radicular, $\mathrm{cm}$

De acordo com o tipo de cultura, foram considerados valores mínimos da profundidade radicular na fase inicial de desenvolvimento. Esses valores aumentam linearmente na fase vegetativa, atingindo o máximo ao chegar à fase de maturação. A partir deste ponto, mantêm-se constantes até o final do ciclo da cultura. Os valores de profundidade radicular na maturação foram adaptados de Doorenbos \& Pruitt (1997); já os valores utilizados na fase inicial foram considerados como sendo $50 \%$ dos valores máximos de profundidade radicular.

Para evitar que ocorresse esgotamento total da umidade do solo, utilizou-se apenas uma fração da capacidade total de água do solo, expressa pela Eq. 7 .

$$
\mathrm{CRA}=\mathrm{CTA} \mathrm{f}
$$

em que:

CRA - capacidade real de água do solo, $\mathrm{mm}$

CTA - capacidade total de água do solo, $\mathrm{mm}$

f - fator de disponibilidade ou esgotamento permitido, adimensional

O fator de disponibilidade (f) depende da demanda climática e da sensibilidade da cultura em resistir ao déficit hídrico no solo.

\section{RESULTADOS E DISCUSSÃO}

\section{O Sistema IRGNET}

Desenvolveu-se um sistema computacional automático de monitoramento, denominado IRGNET, para cálculo e disponibilização, via Internet, da demanda suplementar de irrigação no Estado de Minas Gerais, em tempo quase real, direcionado a produtores rurais, técnicos, extensionistas e cooperativas agrícolas que utilizam irrigação e precisam determinar a lâmina de água a ser reposta à cultura, permitindo o melhor manejo da atividade e a preservação dos recursos hídricos.

\section{Descrição da página do sistema IRGNET na Internet}

Criou-se uma página na Internet para disponibilizar aos usuários os produtos do sistema IRGNET; esta página está hospedada no endereço eletrônico http://www.ufv.br/dea/ irgnet, encontrando-se na página inicial (Figura 2) os seguintes produtos: 1) cadastro do usuário; 2) mapas de ETo; 3 ) mapas de precipitação e 4) área de transferência ("download") do programa Balanço 1.0 e dos dados climáticos formatados, ambos necessários ao cálculo da demanda suplementar de irrigação.

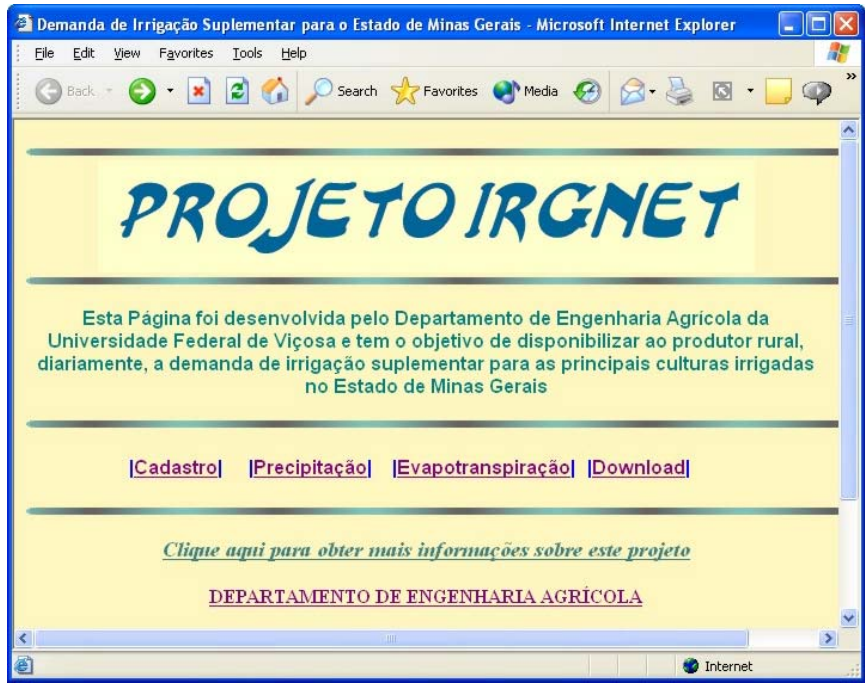

Figura 2. Página inicial do sistema IRGNET na Internet

Na página inicial, a opção "Cadastro" dá acesso a um formulário (Figura 3), que deve ser preenchido com informações sobre o perfil do usuário, auxiliando no aprimoramento do sistema. Outras informações requeridas no formulário são úteis para rodar o programa Balanço 1.0 permitindo, também, um

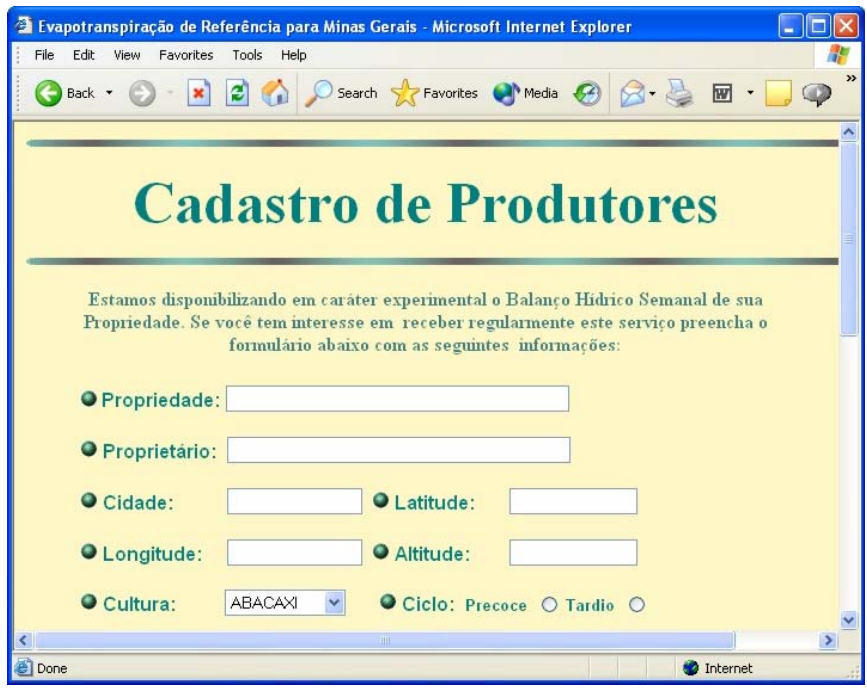

Figura 3. Formulário de cadastro com informações para cálculo do balanço hídrico 
atendimento personalizado ao usuário que tenha dificuldade em operar o programa, sendo os resultados enviados por meio de correio eletrônico ao solicitante.

Na página inicial, a opção "ETo" encaminha para os mapas de ETo, onde são disponibilizados os mapas com totais diários de evapotranspiração de referência, para Minas Gerais, dos sete dias anteriores à data da última atualização (Figura 4). Da mesma forma, a opção "Precipitação" dá acesso aos mapas de precipitação (Figura 5).

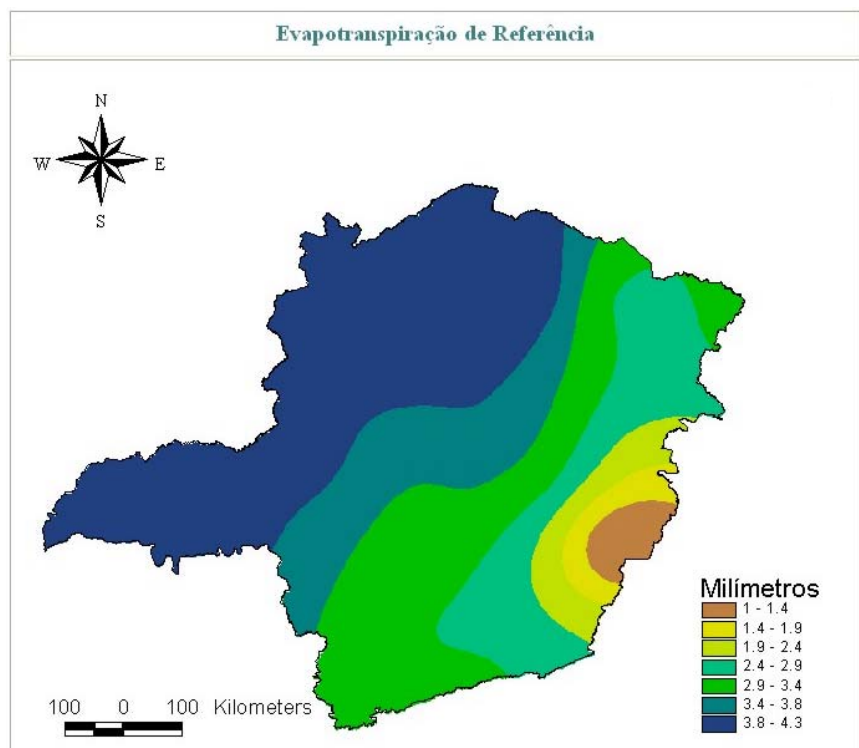

Figura 4. Mapa de evapotranspiração de referência do dia 25/ 06/2001, em Minas Gerais

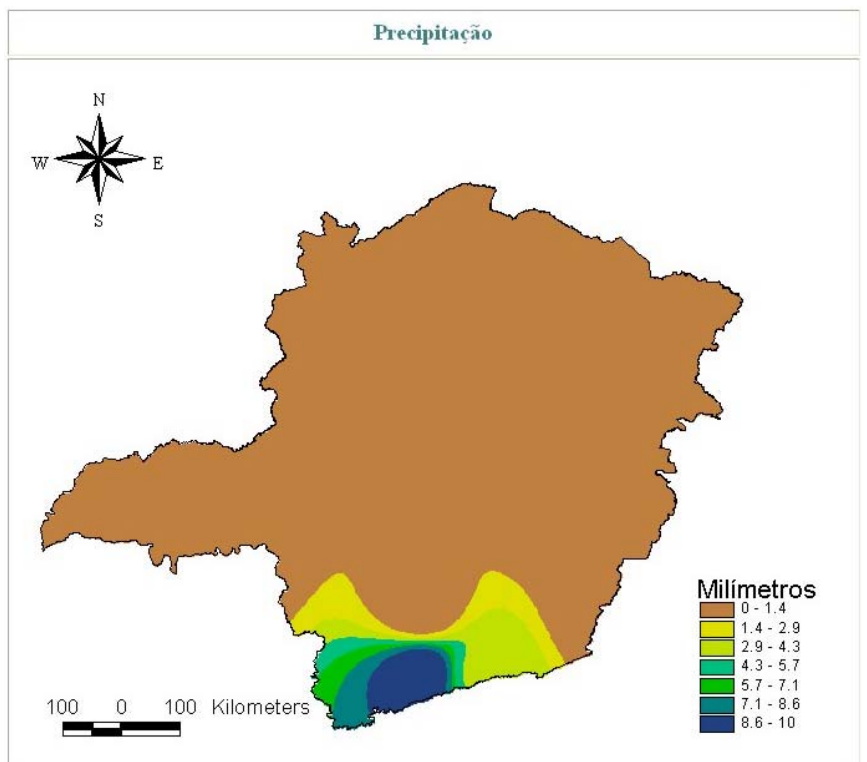

Figura 5. Mapa de precipitação do dia 27/06/2001, em Minas Gerais

Na página inicial, a opção "Download" direciona à área onde é possível descarregar o programa de instalação do Balanço 1.0 e os dados climáticos processados, necessários para sua execução, os quais são atualizados três vezes por semana.

\section{Descrição do programa Balanço 1.0}

O programa computacional Balanço 1.0 foi desenvolvido em linguagem de programação Microsoft Visual Basic 6.0, com o objetivo de calcular o balanço hídrico diário de Minas Gerais, por meio da interpolação de dados de precipitação e de evapotranspiração de referência estimada com dados meteorológicos de 41 estações automáticas situadas no Estado de Minas Gerais e em estados limítrofes. A Figura 6 ilustra a tela inicial do programa Balanço 1.0. Antes de se executar o programa, é necessário que seja feita a sua atualização com dados climáticos mais recentes obtidos através da Internet na página do IRGNET, opção "Download”/“Última atualização dos dados".

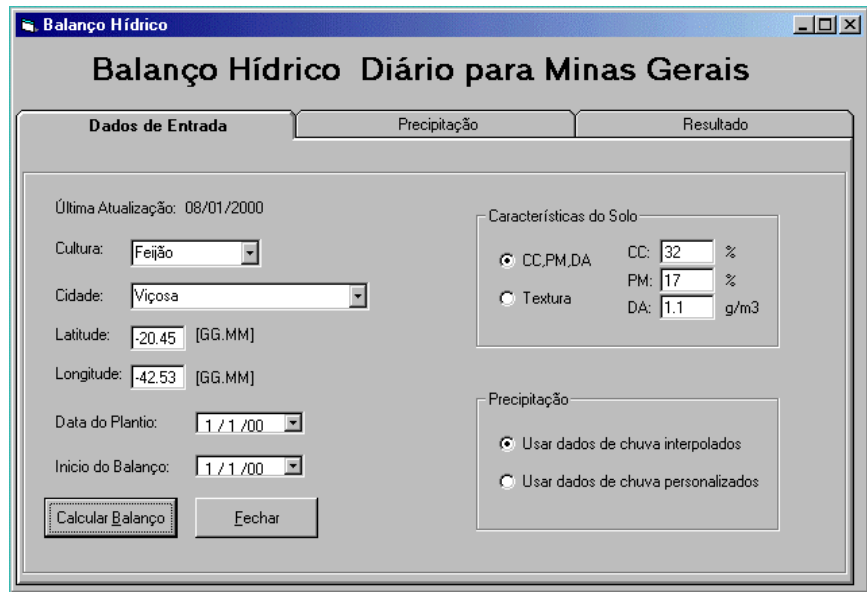

Figura 6. Tela de entrada de dados do programa Balanço 1.0

Na página inicial (Balanço Hídrico Diário para Minas Gerais) do programa Balanço 1.0 existem as pastas Dados de Entrada, Precipitação e Resultado.

Na pasta "Dados de Entrada" há seis campos que devem ser preenchidos; o primeiro campo, "Cultura", refere-se à cultura de interesse, tendo sido cadastradas as 17 culturas mais importantes em relação à utilização de irrigação (abacaxi, algodão, banana, batata, café, cebola, ervilha, feijão, mamão, manga, maracujá, milho, pimentão, soja, tomate, trigo e uva); o segundo campo, "Cidade", é reservado à localidade de interesse, tendo sido cadastrados todos os municípios do Estado, cujas coordenadas de latitude e longitude são preenchidas automaticamente, enquanto o terceiro campo, "Data de Plantio", deve ser preenchido com a data do plantio, para que seja definida a fase fenológica em que se encontra a cultura; já o quarto campo, "Início do Balanço", deve ser preenchido com a data que se deseja ser o início do balanço, para que seja definido o turno de rega; o último campo, "Característica do Solo", deve ser preenchido com as características do solo da propriedade, devendo ser informados a capacidade de campo, o ponto de murcha permanente e a densidade aparente do solo; entretanto, se essas informações não forem disponíveis, pode-se selecionar um tipo de textura do solo (fina, média ou grossa).

Na pasta "Precipitação" existe a opção de se inserir dados de precipitação obtidos na propriedade, uma vez que esse elemento climático é de fácil medida e apresenta grande variabilidade no tempo e no espaço. A utilização desses dados 
gera uma confiabilidade maior nos resultados. Na Figura 7, mostra-se a forma de entrada dos dados de precipitação.

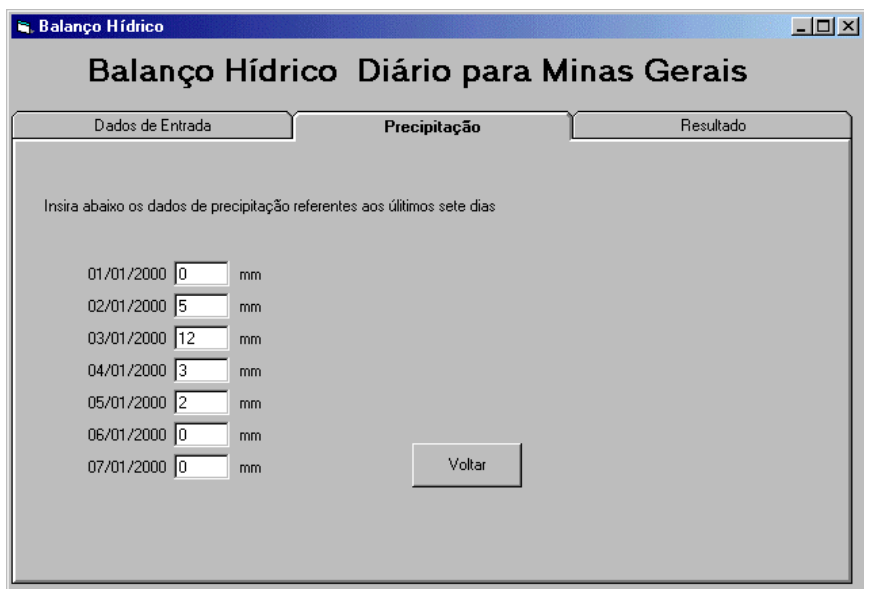

Figura 7. Tela de entrada dos dados de precipitação do programa Balanço 1.0

A pasta "Resultados", contendo os resultados do balanço, é mostrada ao se executar o programa (pasta "Dados de Entrada” opção “Calcular Balanço"). Existe a opção de salvar os resultados num relatório em formato html no computador do usuário (Figura 8). Os resultados são os seguintes: data, número de dias após o plantio (DAP), precipitação (Ppt), evapotranspiração de referência (ETo), coeficiente da cultura (kc), evapotranspiração real da cultura (ETr), lâmina de água armazenada no solo (LAA), demanda de irrigação suplementar (DIS) e demanda de irrigação suplementar acumulada (DISA).

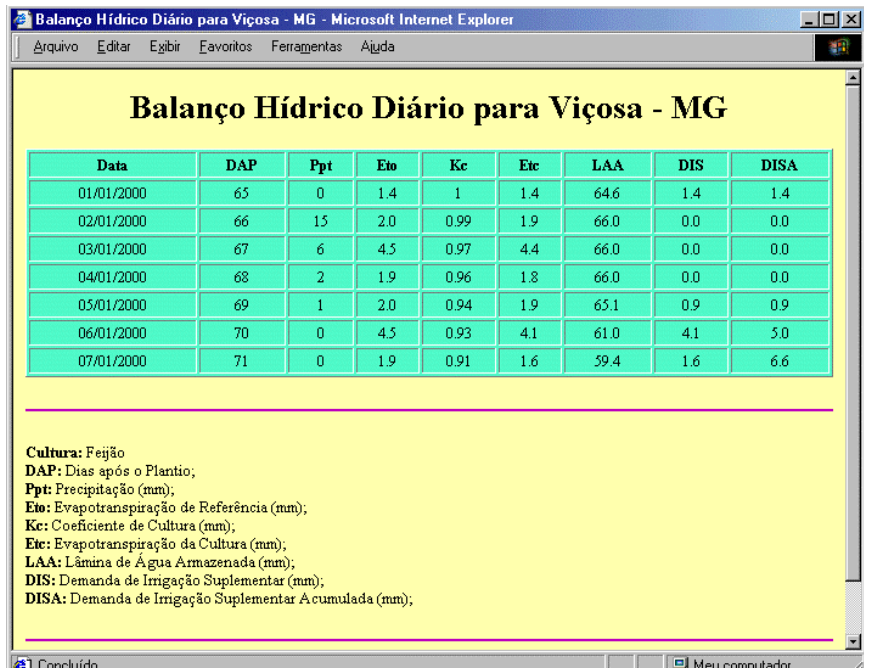

Figura 8. Relatório com os resultados no formato de página da Internet

De maneira geral, no Brasil, especialmente em Minas Gerais, a escolha da lâmina de irrigação a ser aplicada às culturas não tem sido baseada na demanda real existente, que depende das condições climáticas mas, sim, numa lâmina preestabelecida ou em métodos de estimativa limitados. A margem de segurança considerada para o estabelecimento dessa lâmina tem promovido o aumento do custo de produção e o comprome-timento dos recursos hídricos disponíveis. A determinação adequada da lâmina suplementar torna a atividade agrícola mais rentável e sustentável. Assim, o IRGNET, utilizando métodos mais precisos para cálculo do balanço hídrico do solo, tem papel importante na geração de tais informações; entretanto, a maior precisão do sistema é dependente do número de estações climatológicas utilizadas na geoespacialização dos dados. Atualmente, estão sendo utilizadas 41 plataformas de coleta de dados via satélite do CMCD/INPE que, porém, poderão ser incorporados ao sistema dados das estações automáticas da CEMIG. Um dos elementos climáticos com maior variabilidade é a chuva, influenciando a estimativa da demanda fortemente. Pensando nisso foi incorporada, ao sistema, a opção do usuário de fornecer o total de chuva diário, medido em sua propriedade, uma vez que esta medida é de fácil obtenção e exige equipamento de baixo custo.

Uma próxima etapa visando o aperfeiçoamento deste trabalho será a realização de atualizações diárias dos mapas e o desenvolvimento de um programa em plataforma ASP para acessar o banco de dados climático e executar o balanço hídrico em tempo real diretamente do servidor eliminando, portanto, a necessidade de se instalar o programa no computador do usuário.

\section{CONCLUSÕES}

Foi desenvolvido um sistema automático para cálculo da demanda de irrigação suplementar do Estado de Minas Gerais, disponibilizado via rede mundial de computadores (Internet). O acesso ao sistema denominado IRGNET está disponível através do endereço da Internet, http://www.ufv.br/dea/irgnet, sendo atualizado três vezes por semana, disponibilizando mapas temáticos de evapotranspiração de referência e de precipitação diária para o Estado de Minas Gerais, além de um programa computacional para cálculo da demanda de irrigação suplementar, em qualquer localidade mineira.

Diz-se que, em virtude da escassez e da dificuldade de acesso a dados meteorológicos, para cálculo da demanda de irrigação, o sistema IRGNET é uma alternativa viável para corrigir essa lacuna, de forma eficiente; inclusive, é uma forma de haver interação mais efetiva entre o produtor rural e as pesquisas desenvolvidas no meio acadêmico, utilizando-se uma tecnologia que está revolucionando o acesso à informação em tempo real, a Internet.

\section{AGRADECIMENTOS}

Agradecemos ao CMCD/INPE, à CEMIG e ao INMET, pela disponibilização dos dados; ao Conselho Nacional de Desenvolvimento Científico e Tecnológico (CNPq) e à Fundação de Amparo à Pesquisa do Estado de Minas Gerais (FAPEMIG - CAG 2522/98) pelo imprescindível suporte financeiro para a execução deste trabalho. 


\section{LITERATURA CITADA}

Allen, R.G.; Pereira L.S.; Raes, D.; Smith, M. Crop evapotranspiration - Guidelines for computing crop water requirements. Rome: Food and Agriculture Organization of the United Nations, 1998. 300p. Irrigation and Drainage Paper, 56

Bernardo, S. Manual de irrigação. 6.ed. Viçosa: UFV, 1995. 657p. Doorenbos, J.; Kassam, A.H. Efeito da água no rendimento das culturas. Campina Grande: UFPB, 1994. 306p. Estudos FAO: Irrigação e Drenagem, 33
Doorenbos, J.; Pruitt, W.O. Necessidades hídricas das culturas. Campina Grande: UFPB, 1997. 204p. Estudos FAO: Irrigação e Drenagem, 24

Eastman, J.R. IDRISI for windows: user's guide. Massachusetts: Clark University, 1995.367p.

INPE - Instituto Nacional de Pesquisas Espaciais. Plataforma de Coleta de Dados. http://www4.cptec.inpe.br/pdc.htm. Mai. 2003

Minas Gerais. Secretaria de Planejamento. Anuário estatístico de Minas Gerais - 1988 e 1989, v.7, 1990. 896p. 